\title{
ALIENAÇÃO, SOFRIMENTO E ADOECIMENTO DO PROFESSOR NA EDUCAÇÃO BÁSICA
}

\author{
ALIENATION, SUFFERING AND ILLNESS TEACHER'S IN BASIC \\ EDUCATION
}

\author{
Wendel Cristian de Oliveira ${ }^{1}$ \\ Flávia Gonçalves da Silva ${ }^{2}$
}

\section{RESUMO}

Este estudo revela a situação dos docentes que lecionam em três escolas municipais da cidade de Diamantina-MG, por meio de levantamento das condições objetivas do trabalho, bem como sobre a forma como avaliavam estas e a atividade pedagógica. $O$ instrumento utilizado foi um questionário semiestruturado respondido por 61 docentes. Identificamos que as principais queixas dos docentes em relação às condições de trabalho se referiram à estrutura, especificamente a estrutura física, a organização da instituição escolar em que trabalhavam e a precariedade dos materiais didáticos. Metade dos professores solicitou afastamento do trabalho por motivos de saúde, especialmente por diagnósticos de DORT (Distúrbios Osteomusculares Relacionados ao Trabalho), doenças cardiovasculares e psíquicas. Também foi observado o número significativo de professores que estão adoecidos com menos de 5 anos de profissão, e estes relacionam o adoecimento com o processo do trabalho, seja como gerador ou agravante. Além da negligência dos professores em relação ao corpo, especialmente entre aqueles que estão em processo de adoecimento. Tanto 0 a doecimento como o sofrimento dos professores são constituídos pelas alienações, especialmente em três formas: em relação ao produto do trabalho, ao processo do trabalho e a si mesmo.

Palavras-Chave: Adoecimento - Sofrimento - Alienação - Professor.

\section{ABSTRACT}

This study reveals the situation of teachers who teach in three municipal schools in the city of Diamantina, Minas Gerais, through raising the objective conditions of labor as well as on how they evaluated and pedagogical activity. The instrument used was a semi-structured questionnaire answered by 61 teachers. We found that the main complaints of teachers in relation to working conditions referred to the structure, specifically the physical structure, the organization of the school in which they worked and the precariousness of teaching materials. Half of teachers requested sick leave for health reasons, especially for diagnostics of MSDs (Musculoskeletal Disorders Related to Work), cardiovascular and mental illness. Also the significant number of teachers who are diseased with less than 5 years in the profession, and these relate the illness with the working process was observed, either as a generator or aggravating. In addition to the teachers' neglect of the body, especially among those who are getting sick. Both the illness and suffering of 
teachers are made by sales, especially in three ways: as the product of labor, the labor process and himself.

Keywords: Illness - Suffering - Alienation - Teacher.

\section{INTRODUÇÃO}

Este artigo apresenta os resultados de um levantamento sobre as condições de saúde dos docentes da educação básica que lecionam em escolas municipais da cidade de Diamantina (MG). Especificamente, pretendeu-se (re) conhecer quais os aspectos que poderiam vir a tornar o trabalho penoso, que é entendido como o "trabalho gerador de incomodo, esforço e sofrimento físico e mental, [...] em que o trabalhador não tem controle" (SATO, 2004, p.197) sobre o processo de trabalho.

O adoecimento profissional, principalmente entre os docentes vem crescendo de forma alarmante e torna clara a necessidade de alguma intervenção que minimize tal processo. O prazer em ensinar acaba se tornando sofrimento devido às condições para o ensino serem precárias e o apoio aos professores ser inferior ao necessário.

Também há o agravante quando o professor não se encontra preparado para enfrentar algumas circunstâncias no ambiente escolar, seja a ausência de materiais e infraestrutura como de um aluno idealizado (motivado, disciplinado, que se adaptam as propostas metodológicas do professor) que dificultam ou limitam o trabalho. Os conflitos encontrados nesses casos se tornam fatores estressores de forte impacto no professor, dificultando o ensino e o faz repensar no seu processo de formação profissional. O professor se sente insatisfeito, e aliado à formação profissional que pouco oferece possibilidades de novas intervenções, não consegue criar estratégias que contribuam para o processo de superação no trabalho, principalmente no início à docência.

Esses fatores ocasionam o processo de sofrimento, em que este professor não tem mais motivação para lecionar, reproduz as ações do trabalho de forma mecânica, promovendo e acirrando a alienação, já que o significado do trabalho do professor (formar alunos a partir do processo de 
escolarização) é distinto do sentido que este tem para aquele (apenas uma atividade remunerativa que possibilita atender outras necessidades).

Silva (2012, p. 63-64) descreve a alienação enquanto "processo psicológico [...] determinado pelo distanciamento entre os significados e os sentidos, quanto maior for esse distanciamento, mais intenso é o processo de alienação". Nessa relação, podemos discutir o estranhamento do individuo em relação ao processo e produto do trabalho, que no caso do professor, pode ser explicado quando estes não são o que ele esperava ou mesmo o que ele havia se preparado para desenvolver. Além disso, o professor não se reconhece mais no seu trabalho, assim como é citado por Marx:

[...] o homem (o trabalhador) só se sente como [ser] livre e ativo em suas funções animais, comer, beber e procriar, quando muito ainda na habitação, adornos, etc., e em suas funções humanas só [se sente] como animal. $O$ animal se torna humano, e o humano, animal. (...) (MARX apud SILVA, 2007, p. 55)

Outro aspecto da alienação também encontrado no adoecimento docente está relacionando o individuo não reconhecer mais a si mesmo, quando o individuo se vê realizando algo que está distante do que ele havia imaginado. Silva (2012, p.57-58) também discute esse estranhamento de si mesmo quando o individuo apresenta capacidades e habilidades para executar algo, mas não as reconhece, sentindo-se incapaz ou quando exerce o trabalho apenas de acordo com o que é requisitado mesmo possuindo capacidade de ir além.

Um dos aspectos fundamentais relacionados às condições de trabalho do professor se refere ao salário, que é muito inferior a outros profissionais de igual formação ou com formação em nível superior. Rigolon (2013) aponta dados referentes a São Paulo onde a renda mensal de um professor de educação básica é em média de $R \$ 927,00$, enquanto outros profissionais como biólogos e enfermeiros têm remunerações de mais de $R \$ 1.700,00$, farmacêuticos em média $R \$ 2.200$ e dentistas $R \$ 3.300,00$. Brito (2012) relata que a Lei $n^{\circ} 11,738 / 2008$ fixou 0 valor inicial em $\mathrm{R} \$ 950,00$ para professores com formação em nível médio e jornada semanal de 40 horas, em Minas Gerais para uma jornada de 24 horas o valor foi reduzido proporcionalmente. 
A precariedade docente em escola pública é destacada pelo número de professores não efetivos relatado por Rigolon (2013), que ultrapassava 34 mil no estado de São Paulo; mais da metade dos professores em exercício não eram concursados, mostrando um vínculo empregatício precário em que esses professores efetivos não encontravam segurança e estabilidade. O mês de novembro se destaca como o de maior contratação de professores não efetivos para assumir classes cujos professores tenham se afastado ou licenciado por não suportarem as condições de trabalho impostas, solicitando assim licença médica.

As discussões sobre as condições de trabalho do professor não são recentes. Durante o processo de redemocratização da escola pública, tornaram-se crescentes as preocupações relativas à melhoria do ensino no Brasil, principalmente sobre questões da permanência do aluno na escola. Segundo Oliveira (2004) alguns dos principais argumentos para essas modificações foram à instauração de processos participativos por meio da inserção da comunidade escolar na administração das unidades de ensino; a criação de novas formas de organização da educação, com a introdução do currículo com novos conteúdos e de novas práticas pedagógicas; uma visão diferente da profissão docente, que, além de ampliar os níveis de participação e de decisões do profissional da educação, propõe que este deva orientar seu trabalho por uma reflexão crítica sobre sua prática e por compromissos éticos relacionados à superação dos mecanismos intra-escolares responsáveis pela exclusão dos estudantes das camadas populares.

Ludke e Boing (2004) apontam que nas décadas de 1960/1970 o salário representava garantia de vida digna, porém, o desejo de se tornar professor, mesmo naquela época, se encontrava em declínio. Com a baixa remuneração salarial encontrada hoje, subentende-se que é uma perda de tempo investir em educação especialmente no aperfeiçoamento do professor.

Algumas das facetas da precarização do trabalho são relacionadas por Sampaio e Marin: 
professores pelas escolas e questões sobre a carreira no magistério [...]. (SAMPAIO e MARIN, 2004, p.1212)

De fato, um quadro de empobrecimento, deterioração social e as consequentes transformações nos modos de compreender a vida e o mundo em que se vive atualmente, em especial no Brasil e na América Latina, estão em crise com a escola.

Destaca-se também, o aumento da contratação de mão de obra não especializada, impulsionadas pelos contratos temporários nas redes públicas de ensino que ultrapassam em alguns casos 0 de docentes efetivos. Esses cargos temporários não exigem tanta qualificação e é a parcela dos docentes que recebe menos, o que pode influenciar na educação piorando-a no sentido intelectual e motivacional (relacionamento professor e aluno) (OLIVEIRA, 2004).

Oliveira (2004) faz uma observação sobre as inversões do trabalho dos professores, que prescreve que o mesmo assuma funções diferentes do ensinar, sugerindo que este não é o foco principal, além de poderem lecionar conteúdos diversificados em que não são especializados, sem qualquer preparação pedagógica. Somado a isso, iniciativas de interação escolar referente ao processo pedagógico com a comunidade como a ação voluntária desenvolvida por grupos como "amigos da escola", desqualifica e desvaloriza o professor, já que faz parte dessas ações aulas de reforço, ensino de conteúdos extracurriculares em que a formação profissional não é exigida.

As políticas mais recentes sobre plano de carreira docente estão sendo elaboradas tendo como premissa o salário ser proporcional ao seu desempenho, seguindo a linha já adotada por alguns países, como Inglaterra. No Brasil, inicialmente no estado de São Paulo, se instituiu um bônus para os gestores, professores e funcionários das escolas que atinjam as metas estabelecidas pelo Índice de Desenvolvimento da Educação do Estado de São Paulo - IDESP, inspirado no Índice de Desenvolvimento da Educação Básica - IDEB - criado em 2007 para medir a qualidade de cada escola e de cada rede de ensino do Brasil INEP/MEC.

Santos (2004) argumenta sobre como estas medidas têm levado 
os professores a se voltarem para o ensino de conteúdos, uma vez que seu desempenho será medido pelos resultados dos alunos nos testes e não pelos aspectos voltados para a formação humana, além dos processos de avaliação profissional, em que os diretores têm um papel-chave. A relação pessoal entre professores e direção pode tanto favorecer quanto prejudicar a prática pedagógica docente, tornando assim difícil uma avaliação objetiva e imparcial.

Isso leva a uma avaliação dos professores inseridos nessas condições, que a cada dia apresentam mais problemas de saúde, além de se sentirem culpados por todas as falhas ocorridas no processo de escolarização de seus alunos, aumentando o estranhamento dele com o processo e produto do seu trabalho, e até consigo mesmo. O sentimento de culpa é devido àquilo que Ihe foi imposto fazer e que não conseguiram realizar, entre o trabalho prescrito e o realizado, o que leva o docente a não se reconhece no trabalho, caracterizando o processo de alienação.

Discursos e expectativas recaem sempre sobre o professor como se ele pudesse solucionar todos os problemas da educação, mas na prática não são dadas a ele as condições necessárias para alcançar as finalidades da educação. Mesmo tendo como modelo escolar atual representado pelo professor que ensina não apenas puros saberes científicos, mas também valores ideológicos e modelos de comportamento, as condições para alcançar tais finalidades estão longe de serem as mais adequadas.

Outro aspecto a ser considerado no processo de adoecimento é em relação aos diferentes órgãos financiadores e definidores de diretrizes que orientam políticas e projetos educacionais em diferentes partes do mundo, como o Banco Mundial, e órgãos voltados para a cooperação técnica como o Fundo das Nações Unidas Para a Infância - UNICEF e a Organização das Nações Unidas, Para a Educação, Ciência e a Cultura UNESCO.

Algumas diretrizes difundidas nos currículos nacionais e sistema de avaliação posta em funcionamento para medir o desempenho dos estudantes e das escolas, desde a educação básica até o ensino superior, como no caso do Brasil, só fortaleceram os instrumentos de avaliação já existentes e em 
funcionamento. Em 2001 foi aprovado o Plano Nacional de Educação, estabelecendo as bases do Sistema Nacional de Avaliação. Os testes dos diferentes níveis da educação já estavam em funcionamento, como o Sistema Nacional de Avaliação da Educação Básica - SAEB, o Exame Nacional do Ensino Médio - ENEM e o Exame Nacional de Cursos (conhecido como "Provão"), que foi substituído pelo Exame Nacional de Desempenho de Estudantes - ENADE, este último destinado à avaliação do desempenho dos estudantes do ensino superior, e o Sistema de Avaliação da Pós-Graduação.

A criação do Fundo de Manutenção e Desenvolvimento do Ensino Fundamental e de Valorização do Magistério - FUNDEF, a regularidade e ampliação dos exames nacionais de avaliação, a avaliação institucional e os mecanismos de gestão escolar com participação da comunidade são formas de regulação das políticas educacionais com intuito de medir uma suposta qualidade do ensino. Frigotto e Ciavatta (2003) avaliam que os dados coletados no SAEB, mas podemos ampliar para qualquer outro instrumento de avaliação de mesma finalidade que:

\footnotetext{
Se efetivamente analisados como o faz uma pesquisa da Confederação Nacional dos Trabalhadores em Educação, acabariam reprovando o conjunto de políticas do próprio Ministério. Trata-se de uma avaliação que não avalia as condições de produção dos processos de ensino e que não envolve diretamente o corpo docente, portanto não é avaliação e sim uma mensuração simples. A forma de divulgação e o uso desta "medida" como avaliação punitiva pelo Ministério da Educação ou a sua utilização seletiva como critério de acesso ao nível superior e ao emprego ampliam as suas deformações. Ressaltamos que não se trata de negar o direto e o dever do Estado de avaliar, o que está em questão é o método, o conteúdo e a forma autoritários e impositivos de sua implementação. (FRIGOTTO e CIAVATTA, 2003, p 17-18)
}

Esse cenário da educação brasileira na atualidade dificulta cada vez mais a prática pedagógica, independente da concepção teórica desta, especialmente aquela que compreende que o processo educativo é fundamental para a construção de indivíduos que possam transformar a si mesmo e a própria realidade, numa perspectiva emancipatória.

A emancipação se refere às apropriações e objetivações das produções históricas da humanidade, de tal modo que o indivíduo se 
desenvolver cada vez mais. Em síntese, emancipação humana significa a liberdade dos homens serem donos de sua própria história, de terem condições materiais para satisfazerem suas necessidades, bem como a de todos os homens (TONET, 2001).

\section{METODOLOGIA}

O levantamento foi feito em três escolas municipais de Diamantina/MG. As escolas foram escolhidas pela secretaria de educação, por serem as que tinham maior incidência de professores que se ausentaram do trabalho por motivos de saúde entre o segundo semestre de 2012 e o primeiro de 2013. O levantamento com os professores foi feito a partir de um questionário semiestruturado, adaptado a partir do instrumento utilizado por Silva (2007), para levantamento semelhante.

O questionário continha questões sobre caracterização pessoal do professor, a avaliação que faziam do seu trabalho, se havia sofrimento e/ou adoecimento ocupacional e as principais dificuldades que encontravam para o exercício profissional. Para garantir o sigilo, os questionários não foram identificados.

Participaram do levantamento 61 professores, 17 da escola A, 20 da escola B e 24 da escola C. Os professores trabalhavam nos ensinos infantil, fundamental I e II. As escolas ofereciam turnos manhã e tarde, atendiam em média 30 a 45 alunos por sala de aula. Os resultados e discussões foram feitos de forma conjunta, já que não foram identificadas diferenças significativas entre as escolas.

\section{RESULTADOS E DISCUSSÃO}

As idades dos professores eram muito variadas, 25 a 30 anos (11\%), 31 a 35 anos (11\%), entre 36 a 40 anos (17\%), 41 a 45 anos (24\%), 46 a 50 anos (15\%), 51 a 55 anos (11\%), 56 ou acima (2\%) e não responderam (9\%); a renda média desses docentes é predominantemente de 1 a 5 salários mínimos (83,6\%). 
Sobre o tempo de trabalho do professor, as escolas A e B possuem professores com menos tempo de carreira, se comparada com a escola $\mathrm{C}$, conforme pode ser observado no gráfico 1 :

Gráfico 1: Relação por tempo de trabalho

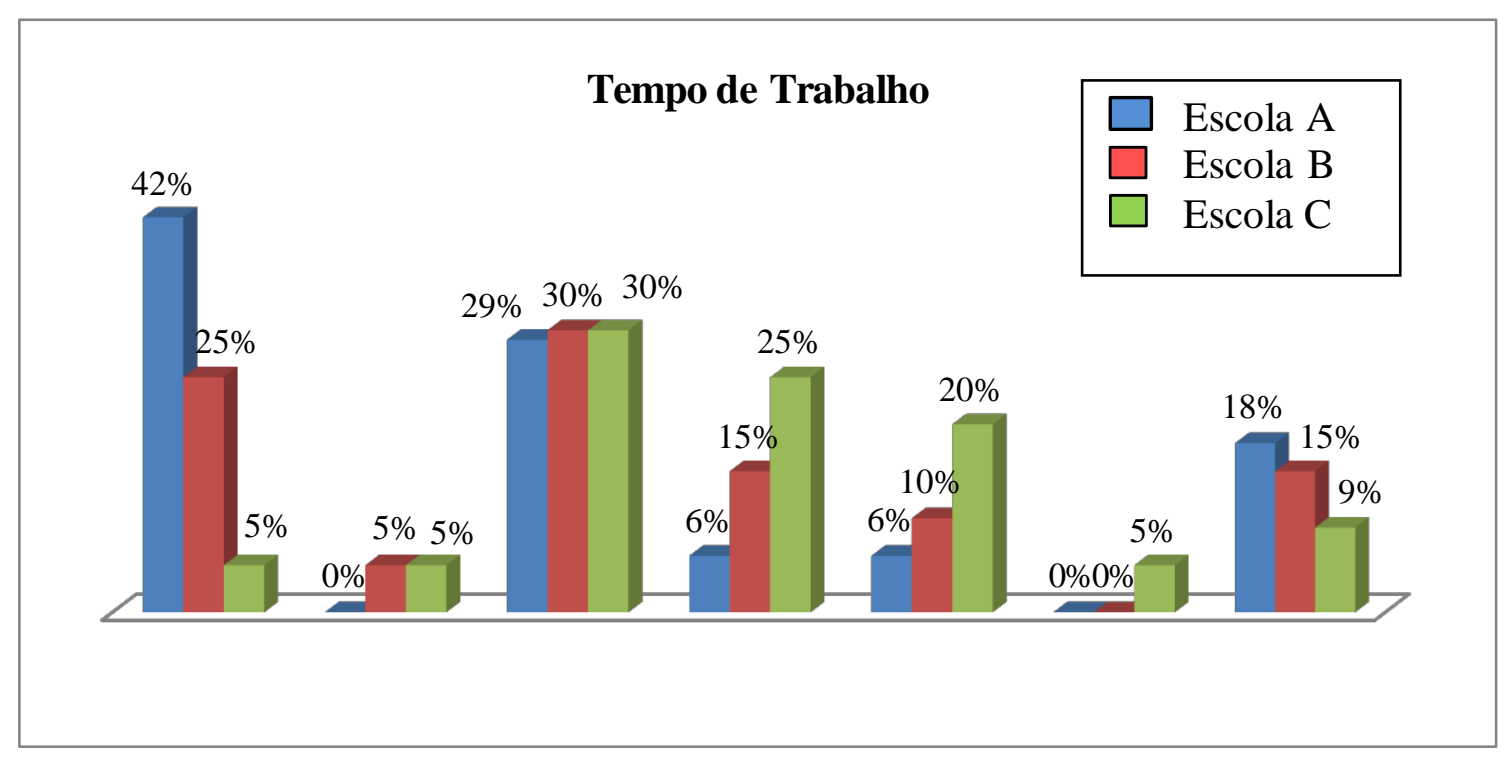

Fonte: Elaboração própria

As escolas A e B tem em grande parte professores com até 5 anos de docência ( $42 \%$ e $25 \%$ respectivamente), este fato revela uma certa preocupação, principalmente pelo fato dessas duas escolas estarem entre as que tiveram um maior número de afastamentos nos últimos anos. Outro aspecto importante é que a escola $C$ se encontra mais próxima ao centro comercial e financeiro do município que as escolas $\mathrm{A}$ e $\mathrm{B}$.

Talvez encontremos na escola $C$ professores com maior tempo de carreira devido a esses docentes gozar de maior liberdade em relação à escolha do local de trabalho, restando locais mais distantes do centro e de suas residências para os professores com menor tempo de docência, já que este é um dos critérios para o professor escolher onde irá lecionar.

Outro fato é esses professores estarem na escola mais antiga, e na de menor tempo de existência estar os professores com menor tempo de carreira. Vale ressaltar que a cidade conta com um transporte público ineficiente de acordo com as necessidades dos professores, e a as ruas são calçadas por pedras, típicas de cidades históricas do século XVII/XVIII, o que dificulta o transito entre essas escolas. 
A familiarização com a atividade dos professores que já possuem maior experiência docente facilita o desenvolvimento desta, possibilitando encontrar estratégias para superar os problemas enfrentados. Sato (2004) relata que a familiaridade é um processo de aproximação gradativa com o trabalho, e que a falta dela pode tornar a atividade ocupacional penosa. Esse momento de iniciação do professor deve conciliar o conhecimento adquirido ao longo da formação com o que encontra na prática profissional, para desenvolver autoconhecimento.

As idades reveladas pelos docentes são na maior parte acima de 35 anos (56\%), e comparando com o tempo de carreira muito pequena na maioria das escolas vemos uma parcela de professores que podem ter optado pela docência já na fase adulta, seja em casos de complemento de conhecimento, como no caso de cuidadoras educacionais (muito comum até os anos 1990 na educação infantil nos grandes centros urbanos; nos municípios pequenos, elas eram frequentes até meados dos anos 2000) que decidiram ampliar para o ensino, ou mães (maioria dos docentes são mulheres) que decidiram pela docência após a maternidade.

Sobre as condições de trabalho que mais incomodam os professores, foram destacadas a estrutura e organização da escola (recursos humano, didáticos, relacionamentos interpessoais), com $62,1 \%$; os alunos e a família (número elevado de alunos por turma, indisciplina e falta de apoio da família), tiveram $20,1 \%$ das respostas; e políticas públicas da educação especialmente faltam de capacitação, desvalorização profissional e salário $(11,4)$.

O fato da estrutura e organização ter ocasionado maior incômodo revela que as condições do ambiente escolar nas três escolas refletem o que professores em todo o Brasil enfrentam, especialmente das escolas públicas.

Sobre o que mais agrada, observou-se uma aparente contradição se comparado com o que foi mencionado com fatores que incomodam no trabalho. Os mesmos fatores foram mencionados, inclusive em ordem de frequência de respostas: estrutura e organização (recursos didáticos, relacionamento entre colegas, apoio da gestão, limpeza, horários) corresponderam a 51\%; alunos e família (aprendizado, reconhecimento do 
trabalho) $30 \%$ e políticas públicas 1\% (13\% não responderam e 5\% deram outras respostas).

Sobre a estrutura, muitos professores destacaram os aspectos desta que estavam preservados (aparelhos de vídeo, playground), bem como a limpeza dos espaços. Sobre as relações interpessoais, como o ambiente escolar é constituído por muitas pessoas, é difícil manter bom relacionamento com todos. Uma hipótese para explicar por que as relações interpessoais agradam e incomodam é que os participantes podem ter se referido a diferentes pessoas, por exemplo, agrada o trabalho ou 0 envolvimento entre os professores, apesar dos gestores da escola, ou o contrário.

É claro que existem muitas dificuldades para o ensino, porém, os professores revelaram grande satisfação ao compreender que o aluno está aprendendo, quando veem na formação destes os resultados de seu trabalho.

Sobre adoecimento, este é um dos maiores fatores de afastamento dos docentes em todo o Brasil, em Diamantina não foi diferente. O número de professores que afirmaram ter algum problema de saúde é de quase $50 \%$, as doenças citadas estão apresentadas no gráfico 2 abaixo:

Gráfico 2: Relação problemas de Saúde

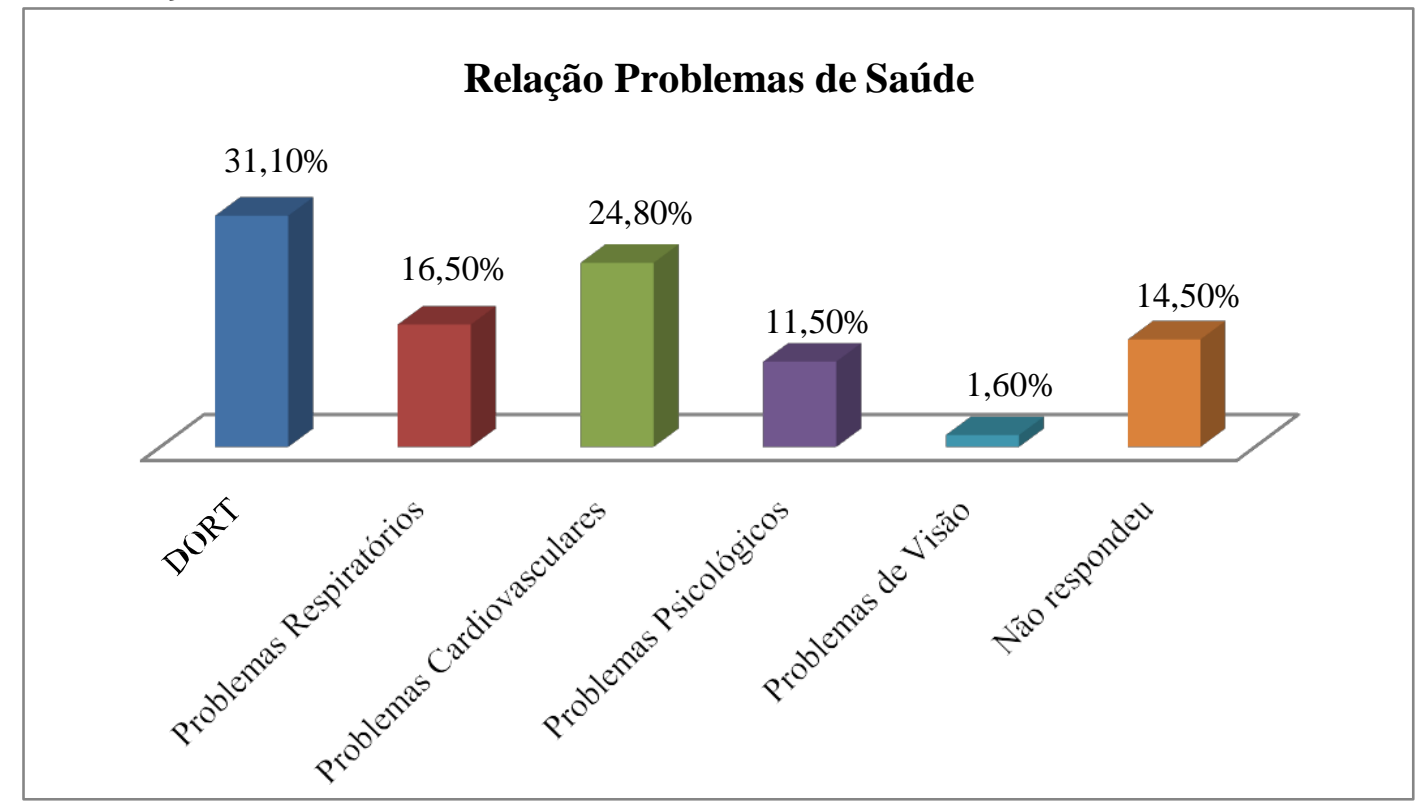

Fonte: Elaboração própria 
Apesar de Distúrbios Osteomusculares Relacionados ao Trabalho DORT ter a maior incidência observa-se que as três outras patologias mais incidentes não têm diferenças porcentuais tão significativas. Destaca-se que os problemas psicológicos mencionados foram depressão, transtorno bipolar e ansiedade, que também vem aumentando em incidência entre os professores no Brasil, como as pesquisas utilizadas para o desenvolvimento deste estudo demonstrou.

Foi associada pelos professores como os principais motivos desse adoecimento a má alimentação, sobrecarga de trabalho, má condição de trabalho, falta da prática de exercícios físicos, atividades repetitivas, e cansaço físico e mental.

Os docentes informaram haver momentos específicos em que a doença se manifesta, entre os principais estão stress $(14,7 \%)$, trabalho excessivo (12\%) e o andar por longas distâncias (18\%). A locomoção por Diamantina é um pouco difícil por grande parte de a cidade ter o calçamento de pedra, muitas vezes irregulares, o que dificulta o trânsito de pedestres e carros. Além disso, a cidade é constituída por várias ladeiras, o que torna o deslocamento a pé mais cansativo. A cidade até oferece transporte coletivo, no entanto, o valor da passagem é alto $(R \$ 2,00)$ tendo em vista a renda per capita do município (R\$589,91 em 2013, segundo o DATASUS ${ }^{3}$ ) e o salário do professor, que é menor que o piso salarial nacional.

O clima (8,6\%) também é um dos fatores relacionados, principalmente no inverno em que a média de temperatura é de $15^{\circ}$, ou mesmo quando as estas variam bruscamente durante o dia. Além disso, destaca-se como agentes promotoras de adoecimento substâncias alergênicas $(8,6 \%)$ e os movimentos repetitivos (16,7\%), responsáveis por muitas das lesões articulares. Em relação à hipertensão, esta muitas vezes pode estar relacionada ao fator hereditariedade, mas, também pode ser um problema adquirido por meio da má alimentação e o stress enfrentado no diaa-dia.

Talvez, se a escola desenvolvesse práticas que favorecessem aos professores e incentivasse alternativas que reduzam o stress e as tensões desenvolvidas no trabalho, provendo assim um profissional que estimule diversas medidas saudáveis e que possam aliviar o sofrimento, os índices 
de afastamento docente diminuiriam.

Ainda sobre o adoecimento, $90 \%$ dos professores adoecidos relacionam esse processo após o inicio à docência, o que pode mesmo ser verdade, se considerarmos que a estrutura da escola foi o aspecto que mais incomodou, e parte do que foi relatado acima está vinculada a ela.

No entanto, mesmo que essa informação não tenha veracidade, para esse levantamento o mais importante é identificar como o professor percebe seu trabalho e se relaciona com ele, construindo significados e sentidos a partir/por meio dele. Se o professor atribui ao seu trabalho o adoecimento, que the mortifica e lhe ocasiona dor, os significados e sentidos que ele atribui/constrói para essa atividade é mediado por essa concepção também.

Por significado entende-se como denominações a objetos/situações construídas histórica e coletivamente pelos homens numa dada sociedade. Tais denominações são expressas na linguagem, especialmente na palavra, e são cristalizadas e generalizadas na realidade (LEONTIEV, 1978).

Segundo o autor supracitado ${ }^{4}$ :

[...] Quando eu percebo um papel percebo este papel real e não a significação "papel". Introspectivamente, a significação está geralmente ausente da minha consciência, ela refracta 0 percebido ou o pensado, mas ela própria não é conscientizada, não é pensada. Este fato psicológico é fundamental. (LEONTIEV, 1978, p. 95)

A partir da citação acima, como o trabalhador significa sua atividade ocupacional que the ocasiona sofrimento ou adoecimento? Mesmo que não seja o trabalho o causador desses processos, quando 0 trabalhador constrói esse significado para a atividade, esta será executada a partir dessa concepção, e sentida de forma bastante peculiar.

A peculiaridade na forma como o significado se apresenta ao indivíduo que mediará à forma como vai vivenciá-lo e executá-lo, se refere aos sentidos. De acordo com Vigotski ${ }^{5}$ (2001), o sentido é “(..) a soma de todos os eventos psicológicos evocados em nossa consciência pela palavra. É um todo complexo, fluido e dinâmico, que tem várias zonas de estabilidade desigual." (VIGOTSKI, 2001, p. 333). Os sentidos podem ser 
manifestados por meio da linguagem, juntamente com o significado, nas mais diferentes formas, como nos gestos, nas pausas, nas entonações de voz, nas contradições de discurso, evidenciando as emoções e sentimentos relacionados ao objeto.

O processo de alienação pode ser explicado quando a distanciamento ou ruptura entre os sentidos e significados atribuídos à atividade ocupacional. No caso da docência, apesar de muitos professores poderem ter como significado de seu trabalho ensinar, transmitir conhecimento ou ser facilitador deste (depende da concepção pedagógica adotada), o sentido pode ser como a atividade que the ocasiona dor e sofrimento, e essas emoções e sentimentos referentes a atividades são mediadoras desta.

Ainda sobre o adoecimento, é relevante considerar os professores participantes que possuem DORT's e que têm menos de 5 anos de docência (alguns estudos revelam que é cada vez maior o número de professores em início de carreira que apresentam adoecimentos relativos à profissão). Uma hipótese que pode ser levantadas para explicar tal fato: os professores não estão sendo preparados para enfrentarem a realidade da escola, devido a formação inicial ser insuficiente para começarem a exercer a docência.

Outra hipótese (na verdade é fato), que não exclui a primeira, é que as condições de trabalho do professor estão cada vez mais adoecedoras, bem como a organização do seu trabalho, e mesmo que tenha uma melhora no processo de formação profissional, é necessário modificar de forma significativa e radical, as condições e gestão do trabalho docente.

O docente que começa a lecionar despreparado não percebe os sinais de que está iniciando um processo de adoecimento, e essa demora na percepção pode fazer com que seja tarde a descoberta. Ou seja, o estranhamento em relação ao próprio corpo é agravado na atividade ocupacional, que vai levar o trabalhador a perceber o corpo por meio da dor. Se antes o corpo era negligenciado (também um processo de alienação), agora ele é percebido, mas não mais de forma ativa e saudável, mas mortificado, que lhe ocasiona sofrimento.

Quando reconhece que o trabalho está causando esse 
adoecimento o docente se afasta, mesmo não estando adoecido, ou em casos como citados anteriormente, vendo que uma sobrecarga está se aproximando o professor recorre aos afastamentos como forma de alívio ao sofrimento vivenciado. Porém, esta estratégia é paliativa e não soluciona os problemas do profissional de educação, já que há necessidade de reorganização do trabalho docente para que não o mortifique.

Ao responderem se haveria alguma forma de evitar o adoecimento ou os seus sintomas, medicamentos, controle alimentar, atividades físicas, terapia, redução do trabalho ou mesmo pouca movimentação foram mencionados.

O número de afastamentos por razão de saúde entre setembro de 2012 e agosto de 2013 foi significativo: até 5 dias (18\%), 10 a 15 dias (27\%), 30 a 45 dias (9\%), 3 meses ou mais (13,8\%), afastado ou em situação de ajuste de função (9\%), e não responderam (23\%), números muito altos em relação ao porte das escolas e o número de professores em cada. Ressalta-se que a quantidade de dias também pode revelar a gravidade do adoecimento e como a atividade ocupacional interfere de forma negativa no trabalho, se as causas que agravam a saúde apontada por eles forem reais. Se agruparmos os dias de afastamento superiores a 10, quase $50 \%$ dos professores que se licenciaram por motivos de saúde necessitavam de um tempo significativo para se recuperarem para trabalhar.

É possível afirmar, a partir dessa constatação que as patologias já estão em estado crônico e com certa gravidade. Mesmo que esse não seja o caso, é fato que o trabalho interfere ou ocasiona processo de sofrimento no professor, sendo o afastamento o único meio que ele encontra para lidar com as dificuldades do trabalho.

Mesmo em meio a esses inúmeros problemas encontrados nas escolas, mais de $90 \%$ dos professores responderam positivamente quando questionados sobre gostarem do trabalho. Os principais motivos referentes a gostar de lecionar estão: gostar do que faz (33,5\%), pela realização de ver as crianças aprendendo (30\%), por gostar das crianças $(6,5 \%)$ ou por ser a docência sua fonte de renda (5\%). 25\% não responderam o porquê de gostar da profissão, porém, a aprovação dos professores refletem que apesar das dificuldades estes ainda encontram motivos para continuar ensinando, e 
que estão diretamente relacionados com a especificidade da atividade docente. Se compararmos com um dos fatores que agradam no trabalho, 0 aluno podemos afirmar que o principal sujeito da ação pedagógica, mesmo com todos as dificuldades que podem ocasionar ao professor, é motivo de prazer no trabalho. No entanto, ao se questionar se gostariam de mudar de profissão, em torno de $40 \%$ afirmou que sim, sendo os principais motivos os fatores: desvalorização (28,7\%), salário, falta de apoio e stress (12,3\% cada), ter outras ambições (8,2\%), entre outros; a maioria dos docentes afirmou que não mudaria de profissão, pela satisfação de ser professor.

Ressalta-se que os fatores relatados pelos professores como motivadores para quererem mudar de profissão são de amplo conhecimento, bem como as intervenções necessárias para modificar 0 quadro. Não é apenas a questão salarial, mas políticas públicas que abarquem as necessidades dos profissionais da educação e proporcione uma maior qualidade de vida, e que reflita na busca por uma maior qualidade no ensino.

Esta questão salarial também tem sido um agravante na relação de escolha de carreira entre os jovens, sem segurança e pouca expectativa de mudanças na situação de carreira docente, o que só contribui para que um número cada vez menor de jovens procure ingressar nos cursos de licenciatura. Em lista divulgada pelo Sistema de Seleção Unificado - SISU principal meio de entrada para as universidades públicas atualmente, os cursos com o menor número de inscritos estão nas licenciaturas dados corroborados em estudo feito por Gatti et al. (2009).

Diversas vezes o professor não consegue compreender 0 seu trabalho, não entende o produto final, ou seja, o docente não reconhece que mesmo diante de alguns alunos que "atrapalham" o desenvolvimento da sua aula também possuem outros que estão compreendendo o conteúdo que vem sendo ensinado. Isso ocorre diversas vezes, principalmente em salas superlotadas e o professor se estressa por não conseguir desenvolver seu trabalho como idealizado. Dessa forma o professor acaba não compreendendo que boa parte de seus alunos estão aprendendo, como é citado por Lima (2010) que relata que o trabalhador já não sente seu trabalho como autorrealização, e, dessa forma se desmotiva e perde 0 
interesse em prosseguir com sua função de educador, ou como colocado anteriormente, o individuo não reconhece o produto do seu trabalho.

Ao procurar pelos professores quais são as perspectivas sobre a profissão docente encontramos as seguintes respostas: espera uma maior valorização (22\%), melhores condições de trabalho (20\%), aprimoramentos (desde a base educacional quanto à estrutura escolar) (24\%), melhores salários $(9,15 \%)$, o que certamente interferiria na qualidade do ensino.

Grande parte do que foi citado pelos participantes tem relação com o que pode ser feito pela prefeitura municipal, condição de trabalho, salário, estrutura escolar; levando em consideração que o salário não foi o mais mencionado, e sim, a valorização que consiste também em melhor remuneração, mas no reconhecimento da importância do professor, respeito pela profissão, entre outros aspectos. O que também pode ter relação é o fato do aperfeiçoamento profissional que está ligado à melhora nas condições de trabalho, que podem facilitar a busca por parte dos docentes.

Gráfico 3: Atividade Física/Bem-estar

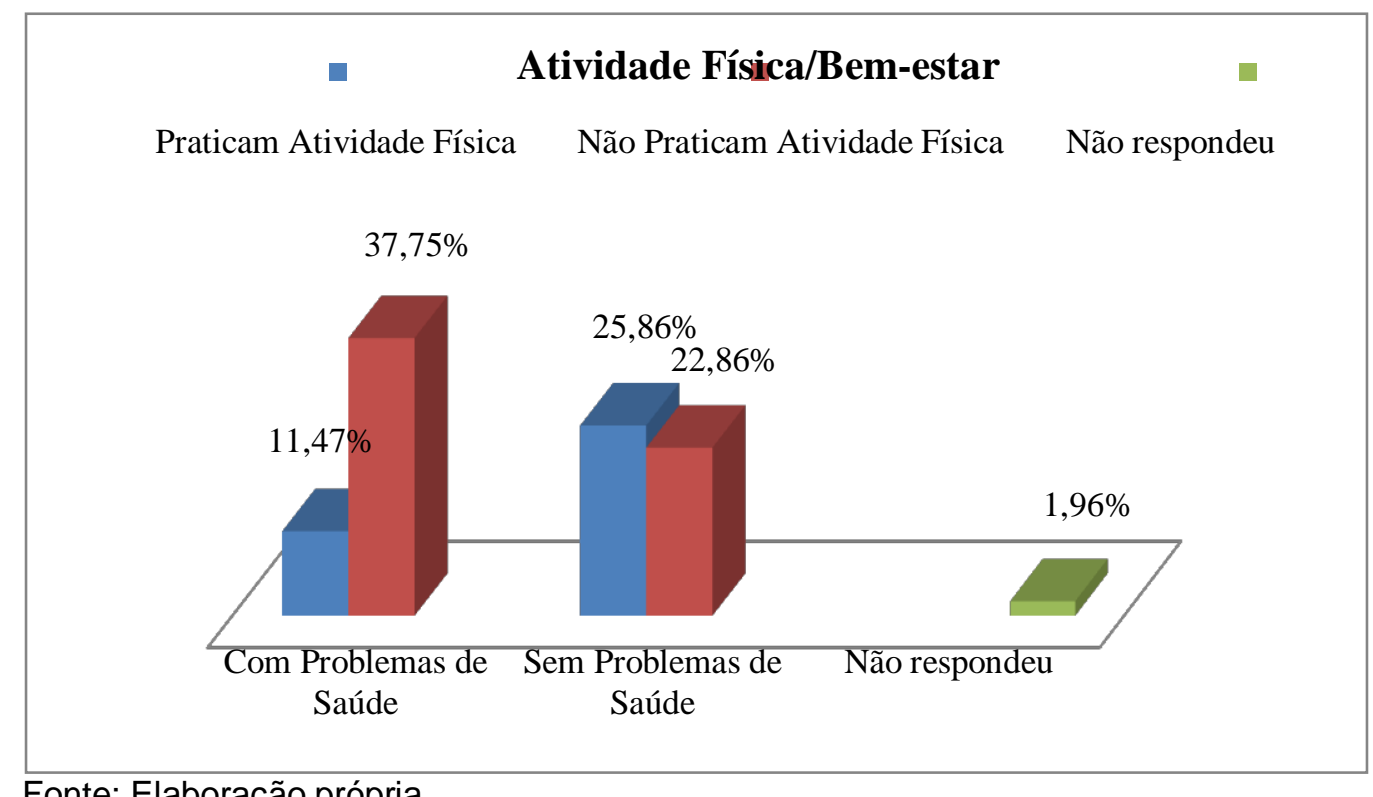

Fonte: Elaboração própria

A relação atividade física/bem estar também foi questionada aos docentes, especificamente sobre a realização de alguma prática corporal. Conforme o gráfico acima demonstra, uma pequena parte dos professores afirmou praticar algum tipo de atividade física, sendo as mais 
citadas realizadas dentro de uma academia e a caminhada, uma solução simples e sem custo algum.

Nota-se que aqueles que têm algum comprometimento na saúde são os que menos realizam atividades físicas. É recomendada a prática de atividades físicas para pessoas que possuam alguns problemas de saúde, desde que sejam acompanhados de profissional capacitado, como é o caso dos hipertensos, em que as atividades físicas regulares, principalmente as aeróbias, contribuem para a melhora de todo o sistema circulatório e pulmonar. No caso das DORT's o sedentarismo pode agravar o quadro destas patologias (tendinite, problemas da coluna, artrite, obesidade, entre outros.), o que mostra a necessidade das atividades físicas, sendo as mais indicadas: caminhada, hidroginástica, alongamentos, relaxamentos, exercícios de fortalecimento.

Garcia (2002, p 167) relata que a educação física é "instrumento eficaz de prevenção e de compensação dos problemas de saúde", sendo estes problemas causados pelas atividades desenvolvidas no trabalho. Mesmo menos reconhecida pelos seus valores e capacidades de enfrentamento às situações de adoecimento que foram citadas na pesquisa, a educação física traz um leque de possibilidades de amenização e prevenção da situação encontrada. Os principais motivos relatados pelos professores para a não prática de atividades físicas é o tempo, ou melhor, a falta deste.

Essas informações podem ser norteadoras para, em um segundo momento, na escola, de forma coletiva, os gestores e educadores encontrarem possíveis soluções para tornar a escola um ambiente adequado às atividades docentes e faça com que esse número de afastamentos diminua. Isso só será possível se houver apoio da gestão escolar e da secretaria.

\section{CONSIDERAÇÕES FINAIS}

Foi possível verificar uma série de fatores correspondentes ao adoecimento/sofrimento dos docentes que participaram do estudo, 
as condições do trabalho não são as adequadas em diversas situações e algumas pequenas medidas poderiam servir para amenizar o adoecimento e sofrimento. As situações encontradas nas três escolas não divergem do cenário educacional brasileiro encontrado nas bibliografias analisadas, porém, por se tratar de escolas municipais, as medidas que podem ser tomadas pelas organizações responsáveis podem ser mais específicas e se fazem necessárias com certa urgência, pois a situação descrita por esses docentes não são as mais indicadas para um bom trabalho ser realizado.

Compreendemos o trabalho com o corpo como uma estratégia importante para amenizar e evitar os agravos decorrentes da atividade ocupacional, aliada a instrumentalização teórico-prática sobre a atuação profissional do professor, e a realidade revelada entre a realização das atividades físicas e os adoecimentos relatados pelos docentes mostram uma nítida melhora a partir da conciliação entre estes.

No entanto, tais práticas devem ser desenvolvidas em processos em que a atividade docente seja problematizada, possibilitando aos docentes e gestores momentos de evidenciarem seus sofrimentos, prazeres, sentimentos em relação ao trabalho. Tais estratégias devem considerar que as especificidades da atividade docente num dado município, nem dada escola, com o conjunto de professores que fazem parte da instituição. São em momentos coletivos que as estratégias para enfrentar a realidade, que implicam em rever, reivindicar melhores condições de trabalho, melhores salários e a própria prática pedagógica, para minimizar o processo de alienação, e consequentemente de sofrimento e adoecimento. Como bem ressaltou Leontiev (1978):

Devemos sublinhar que se bem que se trate de uma inadequação interna da consciência, ela [a alienação] não pode ser eliminada de outro modo a não ser pela transformação prática das condições objetivas que a criaram. Mais precisamente, se estas condições se conservam, esta inadequação só pode ser eliminada à custa de um repúdio pela consciência da vida real ou num processo de luta ativa contra as ditas condições. (LEONTIEV, 1978, p. 131)

O adoecimento e sofrimento do professor além de ser consequência de um processo de alienação, também podem ser uma repulsa às condições degradantes em que a escola, bem como a sociedade em 
geral, promove aos indivíduos.

\section{REFERÊNCIAS BIBLIOGRÁFICAS}

BRITO, V.L.F.A. Financiamento da educação e remuneração de professores: um estudo de caso. Universidade do Estado de Minas Gerais. Ano 15 - n. 19 - junho 2012 - p. 103-128

DATASUS. Diamantina, MG - Renda domiciliar: veja a renda média familiar per capita no seu município Disponível em: <http://www.deepask.com/goes?page=diamantina/MG-Renda-domiciliar: Vejaa-renda-media-familiar-per-capita-no-seu-municipio> Acesso: 07-11-2014.

FRIGOTTO, G. e CIAVATTA, M. Educação básica no Brasil na década de 1990: subordinação ativa e consentida à lógica do mercado. Educação \&Sociedade. São Paulo. n. 82, vol. 24 abril de 2003.

GARCIA, F. M.Trabalho docente em educação física e prática social: relações com a concepção de trabalho capitalista. Revista Brasileira Ciências do Esporte, Campinas, v. 23, n. 2, p. 165-178, jan. 2002.

GATTI, B.A., et. all. A atratividade da carreira docente no Brasil. Fundação Carlos Chagas. São Paulo, SP. Outubro de 2009.

LEONTIEV, A. N. Actividad, consciencia y personalidad. Buenos Aires: Cienciadelhombre, 1978.

LIMA, F.A.P. Alienação do trabalho. DICIONÁRIO: trabalho, profissão e condição docente. Belo Horizonte: UFMG/Faculdade de Educação, 2010.

LUDKE, M.; BOING, L.A. Caminhos da profissão e da profissionalidade docentes. Educação \& Sociedade: Campinas, vol. 25, n. 89, p. 1159-1180, Set./Dez. 2004.

OLIVEIRA, D. A. A reestruturação do trabalho docente: precarização e flexibilização. Educação \& Sociedade. n. 89, vol. 25, set/dez 2004, p. 1127- 1144.

RIGOLON, O.W.; O que muda quando tudo muda? uma análise da organização do trabalho de professores alfabetizadores. Campinas, SP. 2013. Tese de doutoramento.

SAMPAIO, M.M.F.; MARIN, A.J. Precarização do trabalho docente e seus efeitos sobre as práticas curriculares. Educação \& Sociedade. Campinas, vol. 25, n. 89, p. 1203-1225, Set./Dez. 2004.

SANTOS, L.L.C.P. Formação de professores na cultura do desempenho. 
Educação \& Sociedade. Campinas, vol. 25, n. 89, p. 1145-1157, Set./Dez. 2004.

SATO, L. A representação social do trabalho penoso. In M. J. P. Spink (Org.), O conhecimento no cotidiano: As representações sociais na perspectiva da psicologia social. São Paulo: Brasiliense, 2004.

SILVA, F. G. O professor e a educação: entre o prazer, o sofrimento e o adoecimento. São Paulo: PUC, 2007. Tese de doutoramento.

SILVA, F.G. Alienação e o processo de sofrimento e adoecimento do professor: Notas Introdutórias. Revista LABOR nำ, v.1 p. 49-64, 2012.

TONET, I. Educação, cidadania e emancipação humana. Ijuí: Unijuí, 2005. VYGOTSKI, L. S. (1934) Pensamiento y lenguaje. In: VYGOTSKI, L. S. Obras Escogidas. Madri: A Machado libros, 2001, pp.9-348.

\footnotetext{
Discente do curso de licenciatura em Educação Física da Universidade Federal dos Vales do ${ }_{2}$ Jequitinhonha e Mucuri (UFVJM). Email: wendimais@hotmail.com

Doutora em Educação: Psicologia da Educação pela PUC/SP, docente do departamento de Educação Física da Universidade Federal dos Vales do Jequitinhonha e Mucuri (UFVJM). Email: flaviagonsalves@yahoo.com.br

${ }^{3}$ Departamento de Informática Pertencente ao Sistema de Saúde do Brasil, órgão vinculado ao Ministério da Saúde.

${ }^{4}$ Tradução realizada pelos autores.

${ }^{5}$ Tradução realizada pelos autores.
}

RECEBIDO EM: Março de 2015

APROVADO EM: Maio de 2015 